Invited Research Papers

\title{
The turnover of dental microwear texture: Testing the" last supper" effect in small mammals in a controlled feeding experiment
}

\author{
Daniela E. Winkler ${ }^{\mathrm{a}, \mathrm{b}, *}$, Ellen Schulz-Kornas ${ }^{\mathrm{c}, \mathrm{b}, \mathrm{d}}$, Thomas M. Kaiser ${ }^{\mathrm{b}}$, Daryl Codron ${ }^{\mathrm{e}}$, \\ Jennifer Leichliter ${ }^{\mathrm{a}}$, Jürgen Hummel ${ }^{\mathrm{f}}$, Louise F. Martin ${ }^{g}$, Marcus Clauss ${ }^{g}$, Thomas Tütken ${ }^{\mathrm{a}}$ \\ a Institute for Geosciences, Johannes Gutenberg University Mainz, Mainz, Germany \\ ${ }^{\mathrm{b}}$ Center of Natural History, University of Hamburg, Hamburg, Germany \\ ${ }^{\mathrm{c}}$ Department of Cariology, Endodontology and Periodontology, University of Leipzig, Leipzig, Germany \\ ${ }^{\mathrm{d}}$ Department of Human Evolution, Max Planck Institute for Evolutionary Anthropology, Leipzig, Germany \\ ${ }^{\mathrm{e}}$ Department of Zoology and Entomology, University of the Free State, Bloemfontein, South Africa \\ ${ }^{\mathrm{f}}$ Department of Animal Sciences, Ruminant Nutrition, University of Goettingen, Goettingen, Germany \\ ${ }^{\mathrm{g}}$ Clinic for Zoo Animals, Exotic Pets and Wildlife, Vetsuisse Faculty, University of Zurich, Zurich, Switzerland
}

\section{A R T I C L E I N F O}

\section{Keywords:}

Dental wear

Surface texture

DMTA

Diet reconstruction

Diet change

\begin{abstract}
A B S T R A C T
Dental microwear texture (DMT) analysis is commonly applied for dietary reconstruction of vertebrates. The temporal scale on which dietarily informative microscopic wear forms on enamel surfaces is crucial to infer dietary flexibility and seasonality. Microwear is assumed to form shortly before the individual's death, reflecting information pertaining to the last meals consumed ("last supper" effect). In primate feeding experiments, microwear features formed within hours, suggesting rates of turnover within one to two weeks. As DMT formation experiments testing the persistence of microwear three-dimensionally (textures) are still lacking, we test how quickly DMTs form and pre-existing ones are overwritten in a terminal feeding experiment with 72 rats. In two groups of 36, rats received either a standard pelleted diet or the same pelleted diet containing 4\% loess, an aeolian, silt-sized sediment, for 24 consecutive days. Then 6 individuals from each group were sacrificed, while the rest $(n=30)$ were switched to the diet they had not received before. On day $1,2,4,8,16$, and 24 after the diet switch, 5 of the remaining individuals were sacrificed, creating a cohort of $n=5$ each for each time point. We applied DMT analysis on first and second upper molars. For upper second molars, rats show a subsequent change in DMT after the switch, with visible differences from day 2 on. On upper first molars, microwear textures were variable for individuals sacrificed directly after the initial 24-day feeding period, thus obscuring significant differences in diet-induced dental wear. We find turnover faster and more pronounced when switching from loess-containing to standard pellet as compared to the opposite switch. The trend for either decreasing or increasing parameter values after the diet switch approaches a plateau between 16 and 24 days for many DMT parameters, suggesting that, under these experimental conditions, the "last supper" effect needs at least two weeks to overwrite previous DMT patterns.
\end{abstract}

\section{Introduction}

Dental microwear and microwear texture analyses (DMTA) have been widely applied to reconstruct past and present diets in terrestrial mammals such as bovids (Ungar et al., 2007; Merceron et al., 2010; Schulz et al., 2010, 2013; Scott, 2012; Winkler et al., 2013), carnivores (Ungar et al., 2010; DeSantis et al., 2012; DeSantis et al., 2013), primates (Calandra et al., 2012; Schulz-Kornas et al., 2019), hominins
(Scott et al., 2005; Ungar et al., 2008), as well as mammaliaforms (Kalthoff et al., 2019) and recently also fish (Purnell and Darras, 2016), aquatic mammals (Purnell et al., 2017) and Lepidosauria (Winkler et al., 2019a; Bestwick et al., 2019). In these reconstructions, the temporal scale on which microwear is formed and overwritten is crucial for interpretation of intra-specific dietary flexibility, seasonality, environmental change and palaeodietary reconstruction. It further has implications for minimum length of feeding experiments where an

\footnotetext{
* Corresponding author at: Institute for Geosciences, Johannes Gutenberg University Mainz, Mainz, Germany.

E-mail addresses: daniela.winkler@uni-mainz.de (D.E. Winkler), ellen.schulz-kornas@medizin.uni-leipzig.de (E. Schulz-Kornas), thomas.kaiser@uni-hamburg.de (T.M. Kaiser), codrond@ufs.ac.za (D. Codron), leichlit@uni-mainz.de (J. Leichliter), jhummel@gwdg.de (J. Hummel), lfmartin@vetclinics.uzh.ch (L.F. Martin), mclauss@vetclinics.uzh.ch (M. Clauss), tuetken@uni-mainz.de (T. Tütken).
} 
overwriting of wear patterns is assumed (Hoffman et al., 2015).

For more than three decades, researchers have cited the "last supper" effect (Grine, 1986), which implies that microwear, and consequently microwear texture, reflects the last few meals of an individual (e.g., Solounias et al., 1994; Mainland, 1998; Grine et al., 2006; Joomun et al., 2008; Scott et al., 2009; Aiglstorfer et al., 2014; Rivals et al., 2015; Calandra et al., 2016; Martinez et al., 2016; Semprebon et al., 2016). However, in his original publication, Grine was only proposing that “...because microwear patterns can change as diet is altered (Walker et al., 1978; Covert and Kay, 1981; Teaford and Oyen, 1986), the items that were masticated by an individual over a period of time just prior to its death will have a profound effect upon interpretations of its dietary habits from details of tooth wear...". The studies he based his hypothesis on documented formation of in-vivo microwear in vervet monkeys every six weeks (Teaford and Oyen, 1986), in opossums fed cat food or cat food with added plant fibre or chitin after 90 days, and additionally ground pumice after the last 30 days (Covert and Kay, 1981), and in wild populations of hyrax on single individuals that died during the wet or dry season (Walker et al., 1978). None of these original studies allows the conclusion that microwear actually forms within only days, because the shortest experimental duration for which microwear was measured after a dietary switch was six weeks.

Teaford and Oyen (1989) were the first to experimentally address the question of how quickly microwear features, i.e. pits and scratches, form on the enamel surface of teeth. They took dental impressions of vervet monkeys raised on hard (Purina Monkey Chow diet no. 5038 supplemented with apples) or soft food (water softened Monkey Chow and pureed fruit cocktail) three times in four days, establishing a baseline and evaluating $24 \mathrm{~h}$ and $72 \mathrm{~h}$ post-baseline. After $72 \mathrm{~h}$, they found up to $26 \%$ new wear features on enamel shearing facets, and up to $80 \%$ new features on grinding facets, thus interpolating that old microwear features could be replaced completely in 1-2 weeks (Teaford and Oyen, 1989). Studies of dental patients (Teaford and Tylenda, 1991) and Costa Rican howler monkeys (Teaford and Glander, 1991, 1996) demonstrated that microwear formation on a normal diet could vary drastically between species and settings. In a single-subject study on a human, Teaford and Lytle (1996) found 90\% new features on the occlusal surface after one week of feeding on a diet containing mineral residues from sandstone grinding of corn. Romero et al. (2012) found buccal microwear in human subjects to quickly respond to a more abrasive (stone-ground) diet, with $22 \%$ new features formed per week compared to $\sim 1.9-2.8 \%$ per week under a Mediterranean diet. In more recent studies of occlusal microwear in non-human primates (Teaford et al., 2017, 2020), new microwear features were reported to appear after a single feeding bout with brazil nuts. The number of new features positively correlated with the number of brazil nuts consumed in that bout, but the percentage of these new features as compared to the overall microwear features was very small (0-6\%), suggesting that a time period of more than a single meal is required to consistently change a microwear surface. Overall, Teaford et al. (2013) concluded that the formation of microwear patterns is "essentially a complex summary of past events, often with multiple signals superimposed on each other" and that the "last supper" effect "is surely situation-specific and depends on a wide range of factors" (Teaford et al., 2020).

These studies are the only ones systematically addressing the rates of dental microwear formation, all using scanning electron microscopy to visualize microwear features. The conclusions obtained under controlled experimental conditions are, however, limited to non-human primates up to $72 \mathrm{~h}$ after a diet change and a single human subject after one week, and none of these studies actually addressed the question of how quickly dental microwear patterns (now most-commonly assessed via various forms of DMTA) could change.

To address the question of how fast a pre-existing DMT is completely overwritten, we performed a terminal feeding experiment, using rats (Rattus norvegicus forma domestica) as a model organism. In order to determine how fast pre-existing dental wear patterns were overwritten, we tested both the turnover time and dietary abrasiveness when foods were switched from a low abrasive (standard rat pellet) to a higher abrasive diet (standard rat pellet with $4 \%$ loess added) and vice versa. In contrast to previous studies that used microscopic inspection of type and abundance of wear features, we employ DMTA to characterise the complete surface topography of small enamel areas (Ungar et al., 2003; Scott et al., 2005; Calandra et al., 2012; Schulz et al., 2013; Winkler et al., 2019a, 2019b).

\section{Material and methods}

The feeding experiment was performed with ethical approval of the Swiss Cantonal Animal Care and Use Committee Zurich (animal experiment licence no. ZH 135/16).

Adult female WISTAR (RjHan:WI) rats (Rattus norvegicus forma domestica; $n=72$; initial body mass, $254 \pm 9$ g, age 10-11 weeks) obtained from a single breeder and raised on the same pelleted diet were housed in groups of six in indoor stables $\left(0.58 \mathrm{~m}^{2}\right.$ each $)$ built from coated plywood. Each stable was equipped with a floor covered in a thick layer of sawdust, one large wooden shelter, two plastic tubes, a running plate, a climbing ladder, two open dishes, and two nipple drinkers. No extra gnawing material was provided. After a few days, the rats started gnawing at the plywood where nipple drinkers were installed. Gnawing activities typically involved only the incisors, and as we assessed dental microwear textures formed during mastication on molars, the influence of non-diet-related gnawing activities is unlikely. Still, to prevent further gnawing, metal plates were installed over the preferred gnawing spots, visibly reducing gnawing activity.

Water and food were provided for ad libitum consumption. All animals were provided with their designated diet from the first day onward, but the pelleted compound diet provided by the animal breeder was also initially provided and then phased out during a 5-day acclimatisation period. Afterwards, 36 animals received only a standard pellet for rabbits and small rodents (by Granovit AG Kaiseraugst, Switzerland, Protector \#3210) for 24 consecutive days, while the other 36 animals received the same pelleted diet with an addition of $4 \%$ loess as an external abrasive for 24 days. The loess (siliciclastic, silt-sized aeolian mineral dust) is derived from the Late Pleistocene (MIS 3) Schwalbenberg outcrop near Remagen in the Rhine valley, Germany (Schirmer, 2011). It was sieved through $300 \mu \mathrm{m}$ sieves to remove any larger particles to ensure a silt-sized particle size distribution typical for fresh loess in the diet and then added during the pellet production process ( $4 \mathrm{~kg}$ loess for $100 \mathrm{~kg}$ pellets). The loess had an average grain size of 37 ( $S D \pm 3.6) \mu \mathrm{m}$ and consists of $37 \%$ quartz, $25 \%$ phyllosilicates, $16 \%$ calcite, $13 \%$ feldspar, and 5\% dolomite (Fig. S1, Table S1). The loess particles were evenly distributed throughout the pellet, as verified by micro CT scans (Fig. S2). After 24 days, one cohort $(n=6)$ of animals from each group was sacrificed to establish a baseline microwear texture signal for the two different diets. The remaining 30 animals (from now on kept in groups of 5) were switched to the diet they had so far not received (standard pellet to loess-containing pellet, and vice versa). Subsequently, one group of 5 animals per diet was sacrificed on 1, 2, 4, 8, 16 and 24 days after the diet switch (Fig. 1). Individuals that were sacrificed after receiving only one diet are referred to as cohort t0, while the animals sacrificed after the diet switch are referred to as cohort $\mathrm{t} 1, \mathrm{t} 2, \mathrm{t} 4, \mathrm{t} 8, \mathrm{t} 16$, and $\mathrm{t} 24$, depending on how long they received the new diet. Animals were euthanized with carbon dioxide. The skulls were dissected and stored with the bodies frozen at $-20{ }^{\circ} \mathrm{C}$ until maceration. The enzymatic maceration of the skulls was conducted at the Center of Natural History of the University of Hamburg. One aliquot per experimental feed was analysed for their aciddetergent insoluble ash (ADIA) content, and additionally in a second lab for their acid-detergent fibre (ADF) content, to ensure that loess was added correctly and in the right amount to the diet during production. Rectal faecal samples were collected from all dead animals after the experiment and also analysed for their acid-detergent insoluble ash 

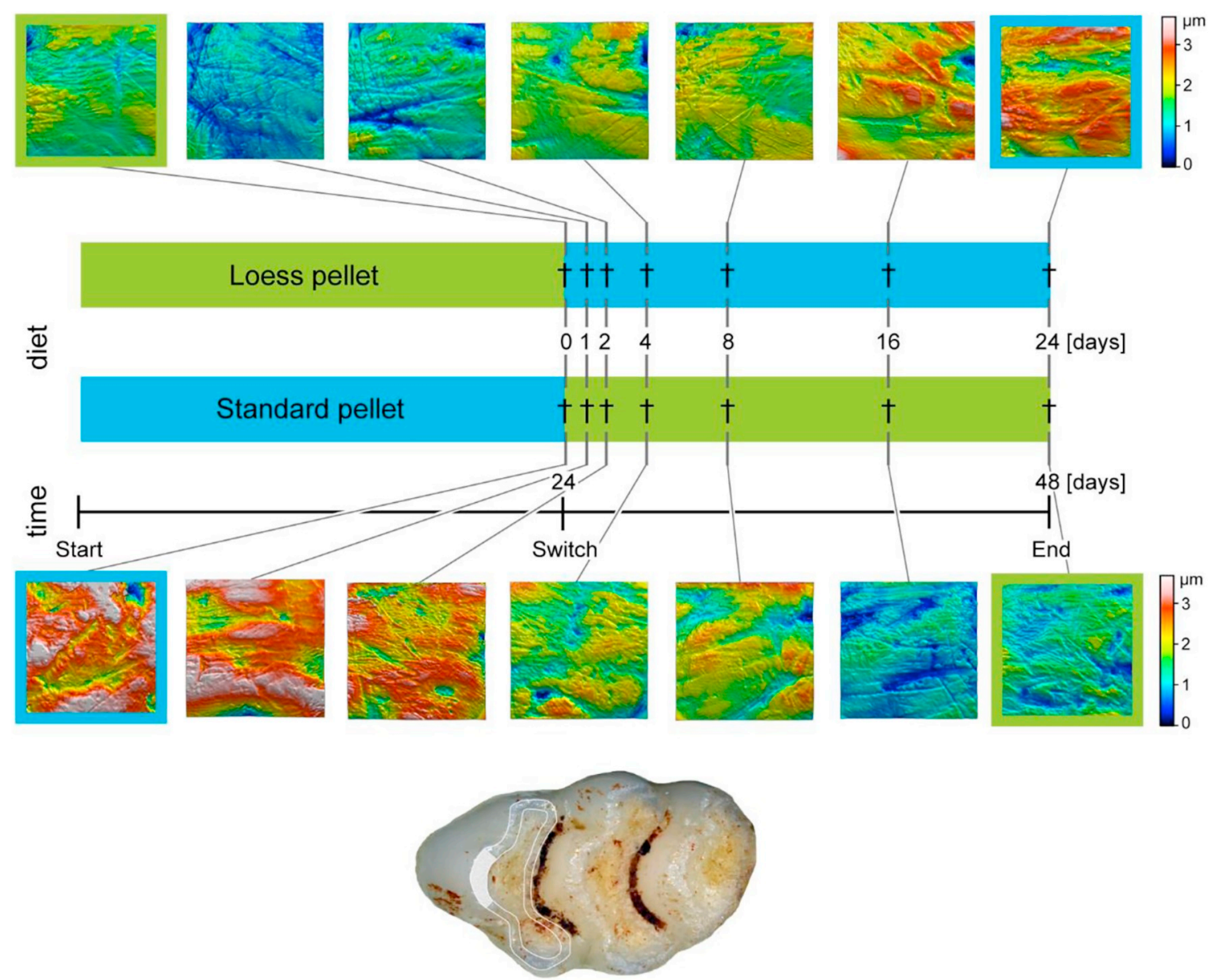

anterior

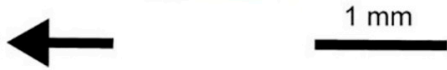

Fig. 1. Graphical representation of experimental design. The two different pelleted diets are represented in green (loess-containing pellet) and blue (standard pellet). The total experimental duration was 48 days. For the first 24 days, two cohorts of 36 animals each received one of the two experimental diets. After the diet switch, for each time point indicated by $\uparrow$, a group of 5 animals was sacrificed, except for t0, where 6 animals were sacrificed. Representative photosimulations of microwear textures for the M2 of one individual per cohort are given for each time point. The measurement position for DMTA is highlighted on the representative upper first molar (adapted from Winkler et al., 2016). (For interpretation of the references to colour in this figure legend, the reader is referred to the web version of this article.)

(ADIA) content (Hummel et al., 2011) in order to ensure that all animals received and ingested their designated diet with or without loess.

Aliquots of the two pellet-types were taken at three different times during the feeding experiment and homogenised in a ball mill. Pellet powder samples were then analysed by X-ray diffraction (XRD) in order to test for the presence of quartz (which composes about $37 \%$ of the loess) in the designated loess-containing pellet, and ensure that the standard pellets did not contain any mineral dust. XRD measurements were performed from 2 theta $5^{\circ}$ to $80^{\circ}$ with $0.03^{\circ}$ per $2 \mathrm{~s}$ using a Seifert XRD 3000 TT diffractometer according to the method described in Sonibare et al. (2010).

\subsection{Dental microwear texture analysis}

Surface texture scans of occlusal surfaces on the first enamel band of the upper first (M1) and second molars (M2) were obtained using the high-resolution confocal disc scanning measurement system $\mu$ surf Custom (NanoFocus AG, Oberhausen, Germany) with a blue LED $(470 \mathrm{~nm})$ and high-speed progressive-scan digital camera $(984 \times 984$ pixel), set to a $100 \times$ long distance objective (resolution in $\mathrm{x}$, $\mathrm{y}=0.16 \mu \mathrm{m}$, step size in $\mathrm{z}=0.06 \mu \mathrm{m}$ ), and processed with MountainsMap Premium v. 7.4.8803 Software (DigitalSurf, Besançon, France, www.digitalsurf.com). Either left or right teeth were measured, depending on preservation of tooth surfaces (some teeth showed defects of the enamel bands or had dirt particles attached that could not be removed). As the default scanning area $(160 \times 160 \mu \mathrm{m})$ exceeds the width of the enamel bands in Rattus, surface scans were cropped manually in MountainsMap Premium to a size of $60 \times 60 \mu \mathrm{m}$, as done previously for black rats from Madagascar (Winkler et al., 2016). We followed the suggested filtering procedure of Schulz et al. (2010, 2013) and took four non-overlapping scans per individual facet (in a few individuals only three scans could be acquired, as enamel bands were too thin or showed damages). We calculated median values for forty-six surface texture parameters, that were quantified using the ISO 25178 (roughness), motif, furrow, isotropy, ISO 12871 (flatness), and scalesensitive fractal analysis (SSFA). Parameters were grouped according to their main characterising feature in the following categories: area, complexity, density, direction, height, peak sharpness, plateau size, slope, and volume (Table S2). One individual of the cohort t4 that received the standard pellet was lost during transport after euthanasia, resulting in a sample size of 4 instead of 5 for this group.

\subsection{Statistics}

In order to facilitate different statistical approaches to data analysis by other researchers, the original data is given as a separate supplementary file. The supplementary material contains the descriptive statistics for all measurements (Tables S3, S4) and the results of statistical 
tests (Tables S5, S6), as well all data visualisation in boxplots (Figs. S3, S4). Additionally, to enable comparison with published data, bivariate scatter plots are provided for surface parameters often used in DMTA studies: a measure of direction (epLsar) vs. a measure of complexity $(A s f c)$, and a measure of furrow density (medf) vs. a measure of furrow depth (metf) (Fig. S5).

Statistical analysis including principal component analyses were carried out using the R software (R Core Team, 2017, version 3.3.1) with the packages xlsx (Dragulescu, 2014), rJava (Urbanek, 2016), doBy (Højsgaard and Halekoh, 2016), R.utils (Bengtsson, 2016), factoextra (Kassambara, 2017), plyr (Wickham, 2011), ggplot2 (Wickham, 2016), Rcpp (Eddelbuettel, 2011, 2013) and rela (Chajewski, 2009). We use the Kaiser-Meyer-Olkin measure of sampling adequacy (value $>$ $0.5)$ and Bartlett's test of sphericity $(<0.05)$ to validate that formal measures for the adequacy of a principal component analysis (PCA) are met and thus conduction of PCAs is justified on our data. PCAs were conducted using the built in function promp() with singular value decomposition (SVD). Detailed results for the PCAs are given in the Electronic Supplement (Table S7).

Significance of DMT differences over time was tested using a combination of three statistical tests following Calandra et al. (2012) and Schulz et al. (2013). As DMT data is generally non-normally distributed, we used the procedure of Wilcox (Wilcox, 2012), applying a robust T1 way heteroscedastic Welch-Yuen omnibus test (Welch, 1938; Yuen, 1974), coupled with a heteroscedastic pairwise "Dunnett's T3 test" (Dunnett, 1980), with significances confirmed using the robust heteroscedastic rank-based test according to Cliff's method (Cliff, 1996) (pairwise comparison with bootstrap). Data were assessed for M1 and M2 separately and compared between cohorts on the same diet and the to cohort that had only received the pre-switch diet for 24 days. The significance level was set to 0.05 .

\section{Results}

When switching from loess-containing pellet to the loess-free standard pellet, the majority of density, height, plateau size, slope and volume parameters show a clear trend for subsequently changing values after the switch (Fig. 2). This trend is more distinct in the M2 as compared to the M1 (Figs. S3, S4), the latter showing more exceptions to this trend, giving the impression of an oscillating microwear texture pattern. Moreover, instead of being most different, the t0 cohort (that only received loess-containing pellet for 24 days) often displays parameter values comparable to the 24 cohort (24 days after the switch to standard pellet), and/or high variability for the M1 (Figs. S3, S4). The trend of subsequently changing parameter values therefore becomes more evident from $\mathrm{t} 1$ on in the M1, while for the M2 it holds for the complete experimental sequence.

A visible difference in parameter values already exists for most parameters between $\mathrm{t} 0$ and $\mathrm{t} 2$ or $\mathrm{t} 4$. Area parameters do not show a visible difference before t16. Statistically, significant differences in parameter values are mostly confirmed between t 0 and t16 as well as between $\mathrm{t} 0$ and $\mathrm{t} 24$ by Cliff's method (Table S5).

For the opposite switch from standard pellet to loess-containing pellet, an opposing trend in subsequently changing parameter values is visible; however, it is less pronounced (Fig. 2). This is observed in both the M1 and M2, with the M2 displaying again a slightly stronger and more obvious trend compared to the M1 (Figs. S3, S4). Descriptive statistics and graphical representations of all parameters for M1 and M2 are given in the supplement (Tables S3, S4; S5, S6; Figs. S3, S4).

In principal component analyses using the best separating DMTA parameters (that showed the most obvious directional changes after the diet switch, and strongest significance) for the M2 (Fig. 3), the first two components explain $80.8 \%$ of the observed variance for the switch from loess-containing pellet to standard pellet, and $78.8 \%$ for the opposite switch. The PCAs highlight the more pronounced, subsequent dental microwear texture turnover when switching from loess-containing pellet to standard pellet. The cohort t0, which only received loesscontaining pellet, is well separated along PC1 from the cohort t24, which had received the standard pellet for 24 days after the switch (Fig. 3). Overall, the overlap between cohorts follows the expected succession, with $\mathrm{t} 0$ overlapping mostly with $\mathrm{t} 1$ and $\mathrm{t} 2$ (and slightly with t8), while $\mathrm{t} 24$ mostly overlaps with $\mathrm{t} 16$. For the opposite switch from standard pellet to loess-containing pellet, the cohorts t 0 and t 24 are less separated, and the cohorts overlap unsystematically, with t24 overlapping mostly with $\mathrm{t} 2$ and $\mathrm{t} 8$.

As most direction parameter show high variability and no clear pattern for either tooth position and either diet switch (Figs. S3, S4), results for this parameter category are not discussed in detail.

\subsection{Area parameters}

When switching from loess-containing pellet to standard pellet, the three area parameters show a continuous increase from t0 to t24 ( $S d a$, Sha, mea; Fig. S4; Table S4) for M2, with t0 being significantly lower than t24 in Sha and mea (Table S5). A similar pattern is found in M1, but with a strong deviation of t0 in mea, and weaker statistical support for the observed pattern (compare Fig. S3; Table S5). For the opposite switch from standard pellet to loess-containing pellet, only mea displays a clear decrease from t0 to $\mathrm{t} 24$, for both M1 and M2 (Figs. S3, S4; Tables S3, S4, S6).

\subsection{Complexity parameters}

Switching from loess-containing pellet to standard pellet, complexity parameters show either an increase from t0 to t24 (Sdr, Asfc; Fig. S4; Tables S4, S5), or a continuous decline from to to t24 (nMotif; Fig. S4) for M2. This trend is less visible in M1, either being obscured by high variability or, for nMotif, by a strong deviation of to from the overall pattern (Fig. S3). When switching from standard pellet to loesscontaining pellet, only nMotif displays a trend of increasing parameter values from t0 to t24, for both M1 and M2 (Figs. S3, S4; Tables S3, S4, S6).

\subsection{Density parameters}

Two out of three density parameters show a decline from to to t24 for M2 (Spd, medf; Fig. S4; Table S4) when switching from loess-containing pellet to standard pellet, with statistical support by Cliff's method for t0 > t24 in Spd and t0 > t8 in medf (Table S5). This also holds true for M1 in medf, and from t1 to t24 in Spd (Fig. S3). In the opposite switch from standard pellet to loess, a weaker trend of increasing values is observed for Spd in both tooth positions (Figs. S3, S4; Tables S3, S4, S6).

\subsection{Height parameters}

For the M2, 16 out of 18 height parameters show a distinct increase between t0 to t24 for the switch from loess-containing pellet to standard pellet (Fig. S4; Table S4), which has statistical support from Cliff's method for $\mathrm{t} 0<\mathrm{t} 16$ (Sa, Sxp, metf) and t0 < t24 (FLTt) (Table S5). In $\mathrm{M} 1$, a clear trend is often obscured by t0 not following the overall pattern, with the exception of metf, which shows a clear increase from t0 to t24 (Fig. S3; Table S4). For the switch from standard pellet to loess-containing, the M2 displays an opposing trend of decreasing values from t0 to $\mathrm{t} 24$ in few parameters (Fig. S4), with statistical support from Cliff's method for t0 $>$ t16 in Sp, meh and FLTV (Table S6). For the M1, no clear pattern can be discerned.

\subsection{Peak sharpness, plateau size and slope parameters}

For the M2, the peak sharpness parameter group (peak curvature, $S p c$ ) increases slightly from t0 to t24 for the switch from loess- 


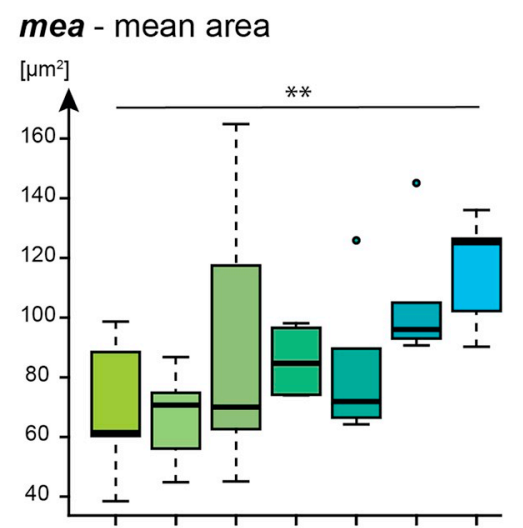

Asfc - Area-scale

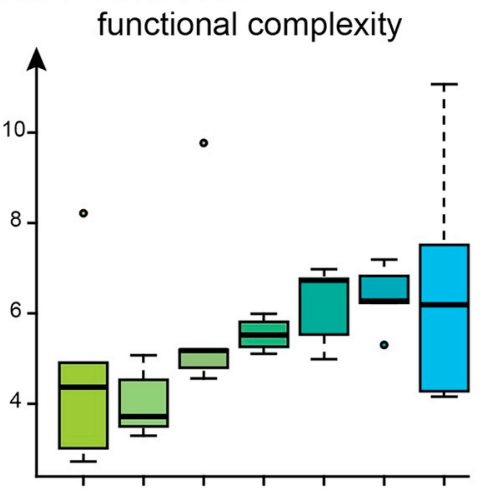

mea - mean area

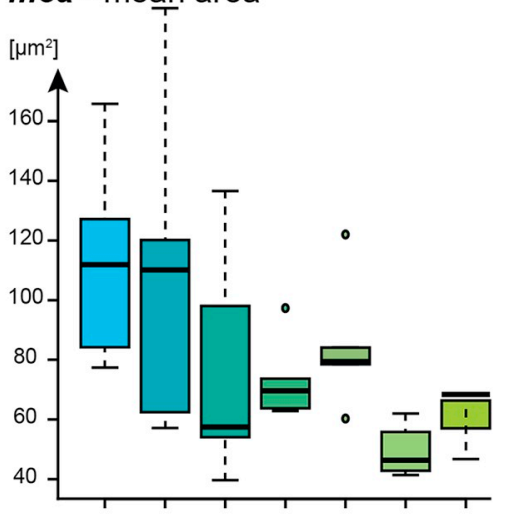

Sa - Mean surface roughness

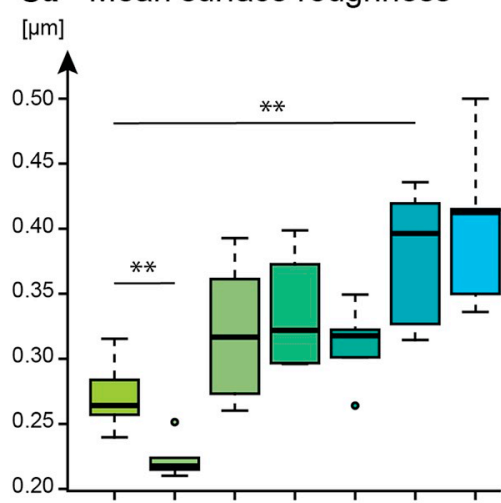

Sa - Mean surface roughness

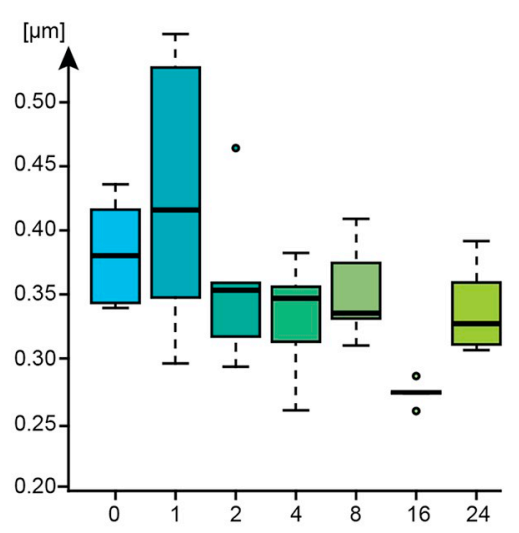

Asfc - Area-scale functional complexity

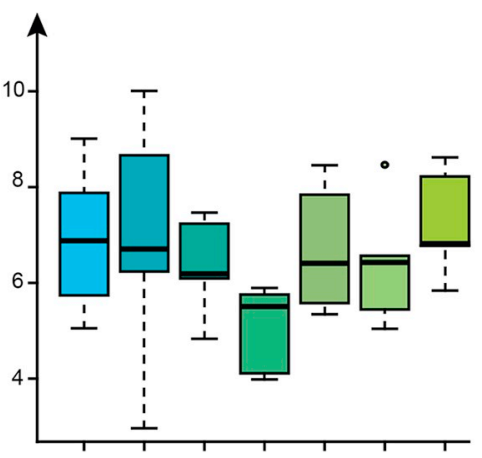

Smc - Inverse areal

[um] material ratio

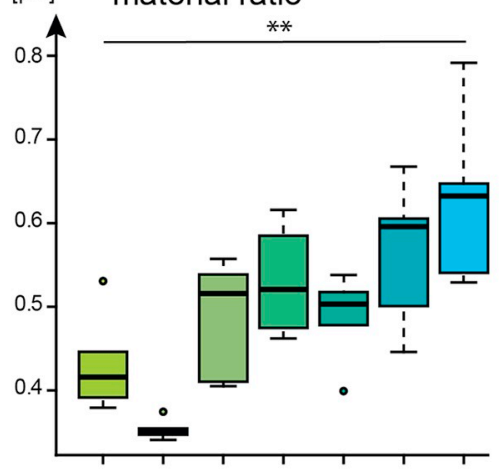

Smc - Inverse areal

[um] material ratio

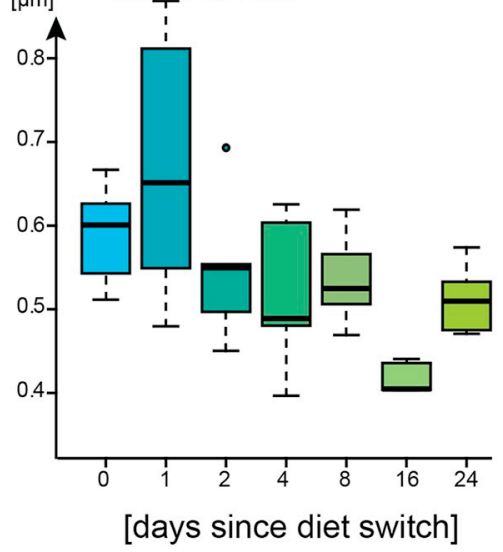

Spd - Density of peaks

[1/ $\left.\mathrm{um}^{2}\right]$

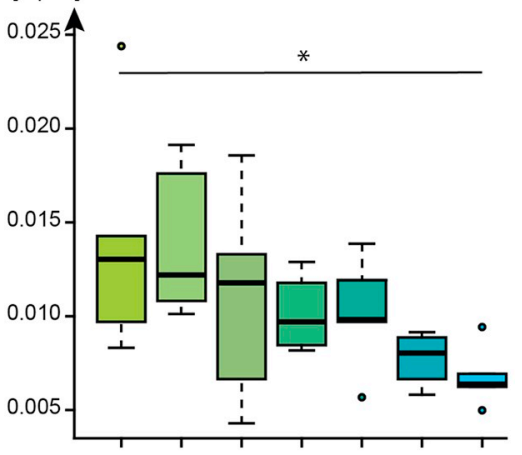

Spd - Density of peaks

[1/ $\left.\mu \mathrm{m}^{2}\right]$

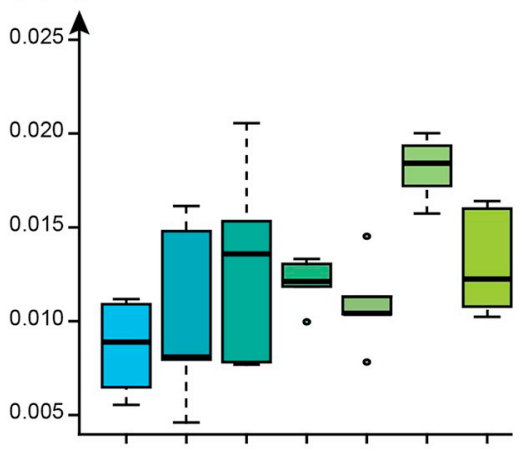

$V v c$ - Void volume of the core $\left[\mu \mathrm{m}^{3} / \mathrm{um}^{2}\right]$

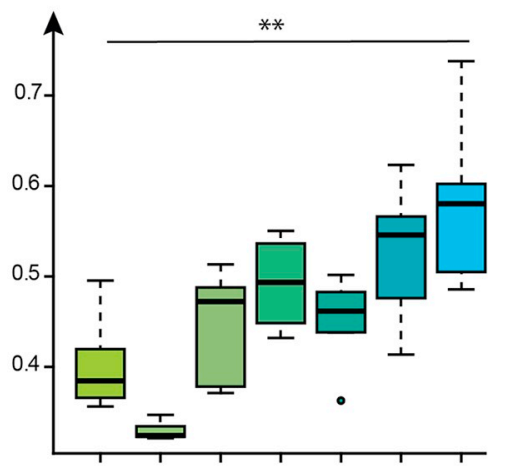

$V v c$ - Void volume of the core

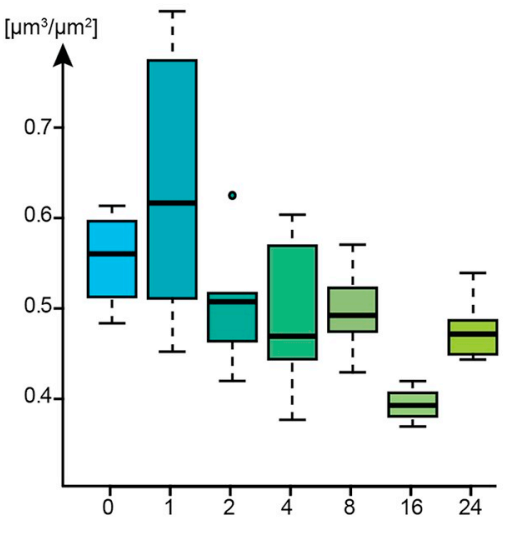




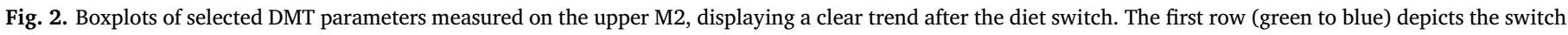

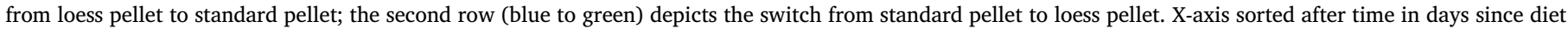

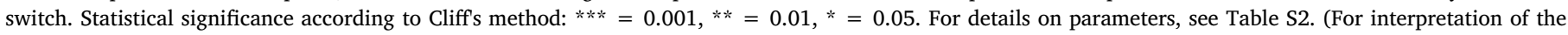
references to colour in this figure legend, the reader is referred to the web version of this article.)

containing pellet to standard pellet, and shows the opposite trend for the switch from standard pellet to loess-containing pellet (Fig. S4; Table S4). This trend is less obvious for M1 (Fig. S3). Plateau size and slope parameters show distinctive trends, either increasing (Smc, $S d q$ ) or decreasing (Smr) from to to t24 for the M2, switch from loess-containing pellet to standard pellet (Fig. S4). For Smr, Cliff's method confirms t0 $<$ t24 (Table S5). For Smr, M1 has a similar pattern, while the other parameters show no clear trend (Fig. S3; Table S3).

\subsection{Volume parameters}

When switching from loess-containing pellet to standard pellet, seven out of eight volume parameters display a clear increase in parameter values from t0 to t24 for M2 (Fig. S3; Table S4). Only for $V v c$, t0 $<$ t24 is confirmed by Cliff's method (Table S5). For M1, the same trend is visible from $\mathrm{t} 1$ to $\mathrm{t} 24$, with t0 falling out of the pattern in all parameters due to high values, except in Shv (Fig. S3; Table S3). When switching from standard pellet to loess-containing pellet, an opposing trend is visible for both M1 and M2 (Figs. S3, S4).

\subsection{ADIA of pelleted diets and rectal faecal samples}

The loess-containing pellet showed higher ADIA (1.7\%) values compared to the loess-free standard pellet (1.5\%) (Table S8). The obtained values were consistent between two different labs where analyses were performed and confirm that loess was correctly added during pellet production.

When switching from loess-containing pellet to standard pellet, a subsequent decrease in ADIA of faecal samples is observed until cohort t4. In cohort t8, ADIA values are higher, and decrease further in cohorts t16 and t24 (Table S9, Fig. S6). For the opposite switch from standard pellet to loess-containing pellet, an increase in ADIA is observed until cohort $\mathrm{t} 2$, followed by a slight decrease from $\mathrm{t} 4$ to $\mathrm{t} 8$, and an increase again at t16. Cohort $\mathrm{t} 24$ is similar in ADIA values to t16 (Fig. S6).

A)

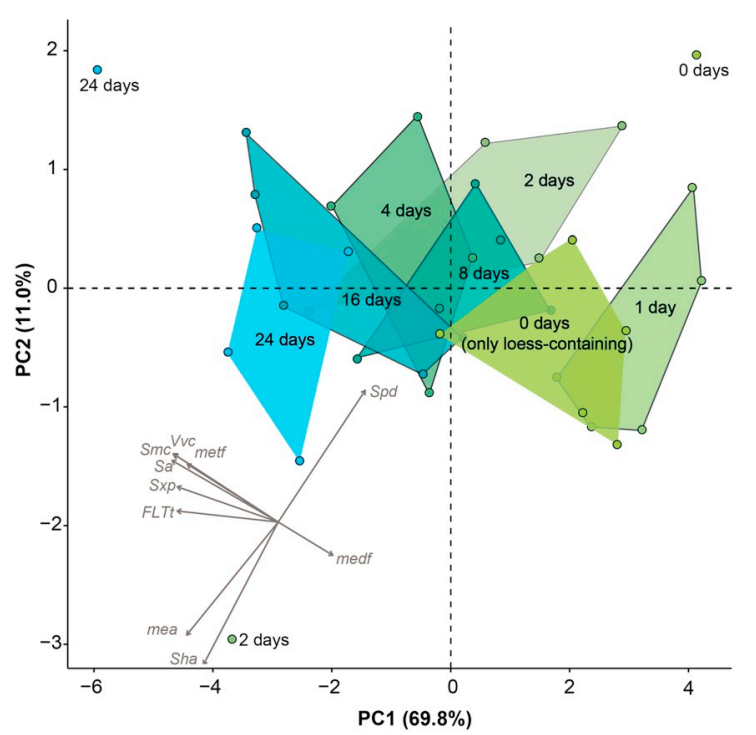

\subsection{XRD analytics of pelleted diets}

In the three aliquots of the loess-containing pellet, a distinct quartz peak is visible between 2 theta of 26.48 and 26.78 . In the three aliquots of the loess-free standard pellet, a small quartz peak is detected (Fig. S7). However, the visible peaks in the standard pellet have an absolute intensity of max. $52 \mathrm{cps}$, which refers to a quartz content lower than 0.5\% (compare to Electronic Supplement of Winkler et al., 2019b). Such low quartz contents are hard to detect, as they almost disappear within the background noise. We thus cannot ultimately decide whether a contamination of the standard pellet with mineral quartz happened during the production process. If this was the case, the amount is so small that no effect on dietary abrasiveness is expected.

\section{Discussion}

The diet switch experiment resulted in clear trends of either subsequently increasing or decreasing values for many DMT parameters, that were more expressed when switching to standard pellet as compared to the opposite diet switch to loess-containing pellet. Still, the opposite diet switch was often accompanied by a mirrored pattern in subsequently changing parameter values (compare Fig. 2; Figs. S3, S4). This is an indication that dental microwear textures are overwritten after the diet switch, and that the ingestion of the new diet lead to predictable, directional change in DMTA. Ideally, the turnover of DMT patterns would be investigated by repeatedly measuring DMT in the same individuals over time before and after a diet switch, as e.g. done in Teaford et al. (2017, 2020) or Romero et al. (2012). Given the model animals of the present study, this approach appeared not feasible. However, in contrast to those previous studies, we did not aim at quantifying how many new features are created after a diet switch, but when the complete microwear texture pattern has changed to such a degree that we can identify a new diet signal. All animals experienced the same conditions in our experiment, and even though individual

B)

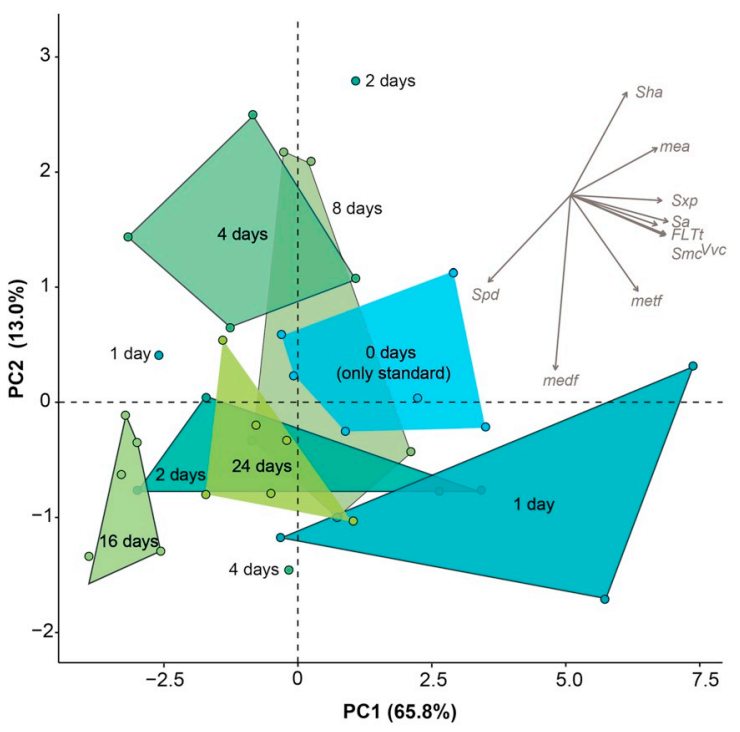

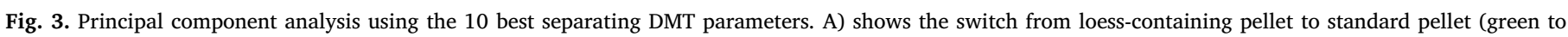

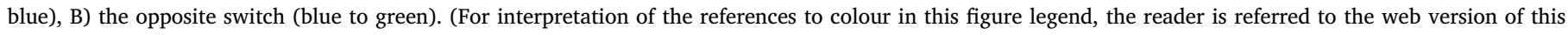
article.) 
differences exist (variability), the overall change in microwear texture can be evaluated and interpreted as turnover time.

The exact duration of turnover (i.e. when a pre-existing microwear texture is completely replaced by a new microwear texture pattern) that can be unambiguously assigned to the new diet depends on the parameter observed. For several height, slope, and volume parameters, a visible difference is already apparent in cohort 2 (just two days after the diet switch), whereas for several area and density parameters (especially for M1), no differences are discernible. Height and volume parameters from the ISO 25178 are calculated using the complementary hill and valley features of the surface texture (International Organization for Standardization, 2012). Therefore, it was to be expected that they show a similar turnover time. We hypothesise that surface peak removal of hill features as indicated by height parameters is quickly effected by the diet, as high peak tips are easily worn down by attrition or hydrodynamic pressure (Schulz et al., 2013). On the other hand, development of peaks and furrows also seems to happen fast. We assume that to keep a surface functionally intact, both removal and creation of particular wear features like peaks and furrows runs in a state of equilibrium. The fast turnover time might also be the reason for the high discriminatory power of height and volume parameter when assessing diets (Schulz et al., 2013; Schulz-Kornas et al., 2019). On the other hand, complexity and area parameters took until t8 to t24 to develop a visible difference compared to the t0 cohort for the switch to standard pellet. When switching to the loess-containing diet, the complexity parameters $S d r$ and Asfc did not show a distinct change. These parameters evaluate the overall distribution pattern of features on the complete surface texture and not just particular wear features. We suggest that overwriting the complete surface texture takes longer, simply because more dental material needs to be removed or at least modified.

The subsequent change, more pronounced when switching from loess-containing to standard pellet, in complexity, density, height, plateau size, slope and volume parameter values continued until t 16 or t24 (16-24 days after the diet switch), usually reaching a plateau between these two time points. For the M2, statistically significant differences to the cohort t0 that only received the pre-switch diet were mostly established 16 or 24 days after the switch. Thus, a complete turnover of DMT can, under our experimental conditions, be identified between two and three weeks after the diet switch.

The two pelleted diets showed different turnover patterns after the switch, with the standard pellet overwriting the previously established "loess-containing pellet signal" faster. By contrast, the overwriting of the "standard pellet signal" by the loess-containing pellet resulted in higher variability of DMT parameters, thus showing a less clear trend after the switch. This is unexpected, as the addition of $4 \%$ loess, an airborne, quartz-containing, silt-sized mineral dust, as an external abrasive was intended to create higher inherent abrasiveness for the loess-containing pellet, which could potentially have resulted in more extreme wear and thus faster turnover. ADIA analyses of diets and faecal samples confirmed that loess was added correctly during the production process and consumed by the rats, and XRD analyses showed no detectable traces (i.e. $<0.5 \%$ ) of quartz in the standard diet. We recognize that several ADIA contents (e.g. low values for t2 and t4 after the switch to standard pellet, Fig. S6) did not match the expected pattern of subsequent ADIA change, however, there was no visible correlation between DMTA and outliers in ADIA. Overall, the pattern of increasing or decreasing ADIA contents match the general patterns reflected in DMTA, and we therefore accept a certain inaccuracy of the ADIA values. Moreover, all animals grew at a comparable rate (Fig. S8), indicating that they consumed similar amounts of pellets, and therefore similar amounts of loess within one cohort. Thus, the loess-containing diet contained more potentially abrasive components than the standard diet. Despite this, the loess-free standard pellet resulted in faster and more complete overwriting of the "loess-containing pellet signal" on the enamel surface than the other way around. Consequently, the notion of how (and how much) external abrasives in the diet lead to macroscopic dental wear, and how dental wear translates to microwear texture, must be reconsidered. At least under our experimental conditions, using an artificial, pelleted diet, the addition of loess at a $4 \%$ level did not result in faster dental wear on a micrometre scale.

A hypothetical post hoc explanation for this observation could be that animals adjust chewing intensity to the proprioceptor feedback they receive during mastication, thereby reducing abrasion and attrition on the loess-containing pellet. In humans, abrasives ( $0.5 \mathrm{~g}$ pumice, average grain size $250 \mu \mathrm{m}$ ) added to a chewing gum led to a lower chewing intensity (Prinz, 2004), and a similar effect was postulated for free-ranging chimpanzees whose faeces indicated a less thorough chewing during a dust-laden wind period (Schulz-Kornas et al., 2019). Possibly, rats switched to the loess-free diet increased their chewing intensity on this diet as compared to the loess-containing diet, accelerating DMT changes, whereas rats switched to the loess-containing diet reduced chewing intensity and hence required more time for DMT changes to develop. In future studies it would be informative to quantify particle size distribution not only of the source material (in the present study, loess), but also in the final diet (pellet) and in the faeces, in order to assess potential changes due to diet production, and due to masticatory and digestive processing. This could provide insight in how thoroughly diets with mineral abrasives are orally processed, and if a sensory feedback mechanism could lead to less thorough mastication.

Additionally, we found tooth positions to have an impact on the diet-induced microwear textures. While the M2 showed a very consistent turnover pattern after the diet switch, the M1 displayed more variability, especially in the to cohort. We need to keep in mind that chewing behaviour and dental wear can vary between individuals, and animals do not provide the expected result (output) when receiving a certain diet treatment (input). We cannot immediately explain why the M2 gives a clearer pattern of wear changes, but our results highlight the importance of multiple measurements for DMTA, preferably on different teeth along the molar tooth row and/or different enamel facets, and sufficiently large sample sizes. This is of great importance to obtain reliable results for dietary reconstruction in fossil species, where samples can be limited and taphonomic or preservation-biases often only allow for measurements on certain teeth and/or a specific site on the tooth. Variability of the microwear texture data, especially from fossil animals, is thus to be expected, and needs to be interpreted with the proper caution. Further work should focus on characterising how much variability exists within one population in order to clarify instances of uncertainty in diet-DMTA correlations.

\section{Conclusions}

We find that there is no immediate" last supper" effect in the overall DMT feature pattern when switching from one diet to another. We conclude that the overwriting of wear features on a micrometre scale takes at least two weeks, and thus feeding experiments analysing microwear or dental microwear texture need to be at least conducted for that time, depending on the dietary changes and taxa involved. Height and volume parameters were most sensitive in recording a diet change and are thus identified as focus parameters to detect short-term diet changes, for example due to seasonal availability of food. As several differences between DMT of the first diet and the second diet were significant only after 24 days in our experiment, we would propose an ideal experimentation duration of three weeks for such feeding experiments. Consequently, the timing of dental microwear (texture) formation needs to be reconsidered, and the "last supper" effect reevaluated. A single meal might leave singular, identifiable traces on the teeth, complete turnover, however, is only established after several weeks. 


\section{Author contributions}

ESK, TMK, DC, MC and TT designed the study, DC, MC and LFM performed the animal experiment, DEW performed the texture measurements, JH provided the nutritional analyses of the diets with additional analyses by JL, DEW and MC wrote the first draft of the manuscript that then received input from all co-authors.

\section{Data availability}

Detailed information on specimens and dental microwear texture results for each scans are included in a supplementary excel file.

\section{Human Rights}

This article does not contain any studies with human subjects performed by any of the authors.

\section{Animal studies}

All institutional and national guidelines for the care and use of laboratory animals were followed.

\section{Declaration of Competing Interest}

The authors declare that they have no conflict of interest.

\section{Acknowledgements}

This project has received funding from the European Research Council (ERC) under the European Union's Horizon 2020 Research and Innovation Programme (Grant Agreement 681450; ERC Consolidator Grant to Thomas Tütken). The work of LFM was funded by Swiss National Science Foundation grant 31003A_163300/1 (to Jean-Michel Hatt) and University of Zurich CanDoc grant FK-16-052 (to LFM). We thank Olaf Jöris for sampling the loess in the field, and Anja Tschudin for support in pelleted diet formulation. We further thank Colette Kramer, Ingeborg Zumbrägel and Anke von Gaza for ADIA analysis of faecal samples and Ralf Meffert and Tobias Häger for XRD analyses. We highly acknowledge the helpful comments and suggestions of three anonymous reviewers.

\section{Appendix A. Supplementary data}

Supplementary data to this article can be found online at https:// doi.org/10.1016/j.palaeo.2020.109930.

\section{References}

Aiglstorfer, M., Bocherens, H., Böhme, M., 2014. Large mammal ecology in the late Middle Miocene Gratkorn locality (Austria). Palaeobiodiv. Palaeoenviron. 94 189-213.

Bengtsson, H., 2016. R.utils: Various Programming Utilities. R Package, Version 2.4.0. Available at. https://CRAN.Rproject.org/package $=$ R.utils.

Bestwick, J., Unwin, D.M., Purnell, M.A., 2019. Dietary differences in archosaur and lepidosaur reptiles revealed by dental microwear textural analysis. Sci. Rep. 9, 11691.

Calandra, I., Schulz, E., Pinnow, M., Krohn, S., Kaiser, T.M., 2012. Teasing apart the contributions of hard dietary items on 3D dental microtextures in primates. J. Hum. Evol. 63, 85-98.

Calandra, I., Labonne, G., Schulz-Kornas, E., Kaiser, T.M., Montuire, S., 2016. Tooth wear as a means to quantify intra-specific variations in diet and chewing movements. Sci. Rep. 6, 34037.

Chajewski, M., 2009. rela: Scale Item Analysis. R Package Version 4.1.

Cliff, N., 1996. Ordinal Methods for Behavioral Data Analysis. Erlbaum, Mahwah, New Jersey.

Covert, H.H., Kay, R.F., 1981. Dental microwear and diet: Implications for determining the feeding behaviour of extinct primates with a comment on the dietary pattern of Sivapithecus. Am. J. Phys. Anthropol. 55, 331-336.

DeSantis, L.R., Schubert, B.W., Scott, J.R., Ungar, P.S., 2012. Implications of diet for the extinction of saber-toothed cats and American lions. PLoS One 7, e52453.
DeSantis, L.R., Scott, J.R., Schubert, B.W., Donohue, S.L., McCray, B.M., Van Stolk, C.A., Winburn, A.A., Greshko, M.A., O'Hara, M.C., 2013. Direct comparisons of 2D and 3D dental microwear proxies in extant herbivorous and carnivorous mammals. PLoS One 8, e71428.

Dragulescu, A.A., 2014. xlsx: Read, Write, Format Excel 2007 and Excel 97/2000/XP/ 2003 Files. R Package, Version 0.5.7. Available at. https://CRAN.R-project.org/ package $=$ xlsx.

Dunnett, C.W., 1980. Pairwise multiple comparisons in the unequal variance case. J. Am. Stat. Assoc. 75, 796-800.

Eddelbuettel, D.F.R., 2011. Rcpp: Seamless R and C ++ integration. J. Statist. Softw 40, $1-18$.

Eddelbuettel, D.F., 2013. Seamless R and C + + Integration with Rcpp. Springer, New York.

Grine, F.E., 1986. Dental evidence for dietary differences in Australopithecus and Paranthropus - a quantitative-analysis of permanent molar microwear. J. Hum. Evol. 15, 783-822.

Grine, F.E., Ungar, P.S., Teaford, M.F., El-Zaatari, S., 2006. Molar microwear in Praeanthropus afarensis: Evidence for dietary stasis through time and under diverse paleoecological conditions. J. Hum. Evol. 51, 297-319.

Hoffman, J.M., Fraser, D., Clementz, M.T., 2015. Controlled feeding trials with ungulates: a new application of in vivo dental molding to assess the abrasive factors of microwear. J. Exp. Biol. 218, 1538-1547.

Højsgaard, S., Halekoh, U., 2016. doBy: Groupwise Statistics, LSmeans, Linear Contrasts, Utilities. R Package, Version 4.5-15. Available at. https://CRAN.R-project.org/ package $=$ doBy.

Hummel, J., Findeisen, E., Südekum, K.H., Ruf, I., Kaiser, T.M., Bucher, M., Clauss, M., Codron, D., 2011. Another one bites the dust: faecal silica levels in large herbivores correlate with high-crowned teeth. Proc. R. Soc. B 278, 1742-1747.

International Organization for Standardization, I, 2012. ISO 25178-2 - Geometrical Product Specifications (GPS) - Surface Texture: Areal - Part 2: Terms, Definitions and Surface Texture Parameters.

Joomun, S.C., Hooker, J.J., Collinson, M.E., 2008. Dental wear variation and implications for diet: An example from Eocene perissodactyls (Mammalia). Palaeogeogr. Palaeoclimatol. Palaeoecol. 263, 92-106.

Kalthoff, D.C., Schulz-Kornas, E., Corfe, I., Martin, T., McLoughlin, S., Schultz, J.A., 2019. Complementary approaches to tooth wear analysis in Tritylodontidae (Synapsida, Mammaliamorpha) reveal a generalist diet. PLoS One 14, e0220188.

Kassambara, A.M.A., 2017. factoextra: Extract and Visualize the results of Multivariate Data Analyses. R package version 1.0.5. https://CRAN.R-project.org/package= factoextra.

Mainland, I.L., 1998. The lamb's last supper: the role of dental microwear analysis in reconstructing livestock diet in the past. Environ. Archaeol. 1, 55-62.

Martinez, L.M., Estebaranz-Sanchez, F., Galbany, J., Perez-Perez, A., 2016. Testing dietary hypotheses of East African hominines using buccal dental microwear data PLoS One 11, e0165447.

Merceron, G., Escarguel, G., Angibault, J.M., Verheyden-Tixier, H., 2010. Can dental microwear textures record inter-individual dietary variations? PLoS One 5, e9542.

Prinz, J.F., 2004. Abrasives in foods and their effect on intra-oral processing: A two-colour chewing gum study. J. Oral Rehabil. 31, 968-971.

Purnell, M.A., Darras, L.P.G., 2016. 3D tooth microwear texture analysis in fishes as a test of dietary hypotheses of durophagy. Surf. Topogr. Metrol. 4, 014006.

Purnell, M.A., Goodall, R.H., Thomson, S., Matthews, C.J.D., 2017. Tooth microwear texture in odontocete whales: Variation with tooth characteristics and implications for dietary analysis. Biosurf. Biotribol. 3, 184-195.

R Core Team, 2017. R: A Language and Environment for Statistical Computing. R Foundation for Statistical Computing, Vienna, Austria.

Rivals, F., Prignano, L., Semprebon, G.M., Lozano, S., 2015. A tool for determining duration of mortality events in archaeological assemblages using extant ungulate microwear. Sci. Rep. 5, 17330.

Romero, A., Galbany, J., De Juan, J., Pérez-Pérez, A., 2012. Brief communication: Shortand long-term in vivo human buccal-dental microwear turnover. Am. J. Phys. Anthropol. 148, 467-472.

Schirmer, W., 2011. Rhine loess at Schwalbenberg II - MIS 4 and 3. E\&G - Quat. Sci. J. 61, 32-47.

Schulz, E., Calandra, I., Kaiser, T.M., 2010. Applying tribology to teeth of hoofed mammals. Scanning 32, 162-182.

Schulz, E., Calandra, I., Kaiser, T.M., 2013. Feeding ecology and chewing mechanics in hoofed mammals: 3D tribology of enamel wear. Wear 300, 169-179.

Schulz-Kornas, E., Stuhltrager, J., Clauss, M., Wittig, R.M., Kupczik, K., 2019. Dust affects chewing efficiency and tooth wear in forest dwelling Western chimpanzees (Pan troglodytes verus). Am. J. Phys. Anthropol. 169, 66-77.

Scott, J.R., 2012. Dental microwear texture analysis of extant African Bovidae. Mammalia 76, 157-174.

Scott, R.S., Ungar, P.S., Bergstrom, T.S., Brown, C.A., Grine, F.E., Teaford, M.F., Walker, A., 2005. Dental microwear texture analysis shows within-species diet variability in fossil hominins. Nature 436, 693-695.

Scott, J.R., Godfrey, L.R., Jungers, W.L., Scott, R.S., Simons, E.L., Teaford, M.F., Ungar, P.S., Walker, A., 2009. Dental microwear texture analysis of two families of subfossil lemurs from Madagascar. J. Hum. Evol. 56, 405-416.

Semprebon, G.M., Rivals, F., Fahlke, J.M., Sanders, W.J., Lister, A.M., Göhlich, U.B., 2016. Dietary reconstruction of pygmy mammoths from Santa Rosa Island of California. Quat. Int. 406, 123-136.

Solounias, N., Fortelius, M., Freeman, P., 1994. Molar wear rates in ruminants - a new approach. Ann. Zool. Fenn. 31, 219-227.

Sonibare, O.O., Haeger, T., Foley, S.F., 2010. Structural characterization of Nigerian coals by X-ray diffraction, Raman and FTIR spectroscopy. Energy 35, 5347-5353. 
Teaford, M.F., Glander, K.E., 1991. Dental microwear in live, wild-trapped Alouatta palliata from Costa Rica. Am. J. Phys. Anthropol. 85, 313-319.

Teaford, M.F., Glander, K.E., 1996. Dental microwear and diet in a wild population of mantled howling monkeys (Alouatta palliata). In: Norconk, M.A., Rosenberger, A.L., Garber, P.A. (Eds.), Adaptive Radiations of Neotropical Primates. Springer, Boston, MA.

Teaford, M.F., Lytle, J.D., 1996. Brief communication: Diet-induced changes in rates of human tooth microwear: A case study involving stone-ground maize. Am. J. Phys. Anthropol. 100, 143-147.

Teaford, M.F., Oyen, O.J., 1986. Dental microwear in vervets raised on different diets. Am. J. Phys. Anthropol. 69, 270.

Teaford, M.F., Oyen, O.J., 1989. In vivo and in vitro turnover in dental microwear. Am. J. Phys. Anthropol. 80, 447-460.

Teaford, M.F., Tylenda, C.A., 1991. A new approach to the study of tooth wear. J. Dent. Res. 70, 204-207.

Teaford, M.F., Ungar, P.S., Grine, F.E., 2013. Dental microwear and paleoecology. In: Sponheimer, M., Lee-Thorp, J.A., Reed, K.E., Ungar, P. (Eds.), Early Hominin Paleoecology. University of Colorado Press, Boulder.

Teaford, M.F., Ungar, P.S., Taylor, A.B., Ross, C.F., Vinyard, C.J., 2017. In vivo rates of dental microwear formation in laboratory primates fed different food items. Biosurf. Biotribol. 3, 166-173.

Teaford, M.F., Ungar, P.S., Taylor, A.B., Ross, C.F., Vinyard, C.J., 2020. The dental microwear of hard-object feeding in laboratory Sapajus apella and its implications for dental microwear formation. Am. J. Phys. Anthropol. 1-17.

Ungar, P.S., Brown, C.A., Bergstrom, T.S., Walker, A., 2003. Quantification of dental microwear by tandem scanning confocal microscopy and scale-sensitive fractal analyses. Scanning 25, 185-193.

Ungar, P.S., Merceron, G., Scott, R., 2007. Dental microwear texture analysis of Varswater bovids and early Pliocene paleoenvironments of Langebaanweg, western Cape Province, South Africa. J. Mamm. Evol. 14, 163-181.

Ungar, P.S., Grine, F.E., Teaford, M.F., 2008. Dental microwear and diet of the Plio-
Pleistocene hominin Paranthropus boisei. PLoS One 3, e2044.

Ungar, P.S., Scott, J.R., Schubert, B.W., Stynder, D.D., 2010. Carnivoran dental microwear textures: Comparability of carnassial facets and functional differentiation of postcanine teeth. Mammalia 74, 219-224.

Urbanek, S., 2016. rJava: Low-Level R to Java Interface. R Package Version 0.9-8.

Walker, A., Hoeck, H.N., Perez, L., 1978. Microwear of mammalian teeth as an indicator of diet. Science 201, 908-910.

Welch, B.L., 1938. The significance of the difference between two means when the population variances are unequal. Biometrika 29, 350-362.

Wickham, H., 2011. The split-apply-combine strategy for data analysis. J. Stat. Softw. 40, $1-29$.

Wickham, H., 2016. ggplot2: Elegant Graphics for Data Analysis. Springer-Verlag, New York, pp. 2016.

Wilcox, R.R., 2012. Introduction to Robust Estimation and Hypothesis Testing. Elsevier Academic Press, London.

Winkler, D.E., Schulz, E., Calandra, I., Gailer, J.P., Landwehr, C., Kaiser, T.M., 2013. Indications for a dietary change in the extinct bovid genus Myotragus (Plio-Holocene, Mallorca, Spain). Geobios 46, 143-150.

Winkler, D.E., Andrianasolo, T.H., Andriamandimbiarisoa, L., Ganzhorn, J.U., Rakotondranary, S.J., Kaiser, T.M., Schulz-Kornas, E., 2016. Tooth wear patterns in black rats (Rattus rattus) of Madagascar differ more in relation to human impact than to differences in natural habitats. Ecol. Evol. 6, 2205-2215.

Winkler, D.E., Schulz-Kornas, E., Kaiser, T.M., Tütken, T., 2019a. Dental microwear texture reflects dietary tendencies in extant Lepidosauria despite their limited use of oral food processing. Proc. R. Soc. B 286, 20190544.

Winkler, D.E., Schulz-Kornas, E., Kaiser, T.M., De Cuyper, A., Clauss, M., Tütken, T., 2019b. Forage silica and water content control dental surface texture in guinea pigs and provide implications for dietary reconstruction. Proc. Natl. Acad. Sci. U. S. A. $116,1325-1330$

Yuen, K.K., 1974. The two-sample trimmed $t$ for unequal population variances. Biometrika 61, 165-170. 